Revista lus et Praxis, Año 16, N² 2, 2010, pp. 353 - 382

ISSN 0717 - 2877

Universidad de Talca - Facultad de Ciencias Jurídicas y Sociales

"Aplicación del procedimiento de tutela de derechos fundamentales en el suministro de trabajadores"

L. Iván Díaz García

\title{
APLICACIÓN DEL PROCEDIMIENTO DE TUTELA DE DERECHOS FUNDAMENTALES EN EL SUMINISTRO DE TRABAJADORES*
}

\author{
APPLICATION OF THE FUNDAMENTAL RIGHTS PROTECTION \\ PROCEDURE IN WORKER'S SUPPLY
}

L. IVÁn Díaz García**

\begin{abstract}
RESUMEN
La Ley No 20.087 incorporó al Código del Trabajo, en el marco de una nueva regulación procesal laboral, el procedimiento de tutela destinado a amparar, entre otras situaciones, los derechos fundamentales en el ámbito laboral. Por su parte, la Ley N 20.123, también incorporada al Código del Trabajo, reguló las relaciones jurídicas entre las empresas de servicios transitorios, las empresas usuarias de los servicios de los trabajadores suministrados por aquéllas y los trabajadores suministrados para prestar servicios en estas últimas. En ese contexto, el presente trabajo intenta dilucidar si la empresa usuaria que vulnera los derechos fundamentales de los trabajadores que se le han suministrado, es sujeto pasivo del referido procedimiento de tutela. Para estos efectos se analizan, sucesivamente, cada uno de los tres requisitos de aplicación de dicho procedimiento, esto es, (1) que en el contexto de la relación laboral (2) se vulneren los derechos fundamentales protegidos

(3) como consecuencia del ejercicio de las facultades del empleador.
\end{abstract}

\section{ABSTRACT}

Law N 20.087 incorporated to the Labor Code, in the context of a new regulation of the labor procedure, the procedure for fundamental rights protection that seeks to protect, among other situations, fundamental rights in the labor environment. On the other hand, law No 20.123, also incorporated to the Labor Code, regulated juridical relationships among Temporary Service Companies, the companies that use the services provided by the workers supplied by this companies and the workers themselves. In this context, this paper seeks to elucidate if the company that uses the services that violates the supplied worker's fundamental rights, is a passive subject

\footnotetext{
* El autor agradece a Laura Cifuentes, Daniza Medina, Rebeca Peña y Catalina Salvo, sin cuyas ideas seguramente este trabajo jamás habría visto la luz. Agradece también los comentarios de Juan Pablo Beca, José Miguel Fernández y Jordi Delgado, que han permitido mejorar su trabajo. Por cierto, las falencias que subsistan son de exclusiva responsabilidad del autor. Trabajo recibido el 10 de septiembre y aprobado el 20 de octubre de 2010.

** Abogado, Pontificia Universidad Católica de Chile; Doctor en Derecho por la Universidad Carlos III de Madrid, España; Académico en la Facultad de Ciencias Jurídicas de la Universidad Católica de Temuco. Correo electrónico: ivandiaz@uctemuco.cl.
} 
of the above mentioned protection procedure. For this purpose we analyze each one of the three requirements for using this procedure, this is, (1) that in the context of a labor relationship (2) protected fundamental rights are violated (3) as a consequence of the use of the employer's faculties.

PaLABRAS ClaVE

Derechos Fundamentales, Trabajador Transitorio, Procedimiento de Tutela

KEY WORDS

Fundamental Rights, Temporary Worker, Protection Procedure

\section{INTRODUCCIÓN}

\section{Planteamiento del problema}

El respeto, promoción y protección de los derechos fundamentales ha constituido una opción central del Derecho chileno desde la reinstalación de la democracia en el país en 1990. En el ámbito laboral esta tendencia también contó con claras, aunque focalizadas manifestaciones. En efecto, en los últimos años se han incorporado al Código del Trabajo, en adelante el Código, disposiciones que perfeccionan la prohibición de discriminación ${ }^{1}$, que establecen como límite de las facultades del empleador el respeto de los derechos fundamentales de los trabajadores ${ }^{2}$, y que exigen fundar las relaciones laborales en un trato compatible con la dignidad de la persona ${ }^{3}$, entre otras.

Sin embargo, sólo con la Ley No 20.087, publicada el 3 de enero de 2006, que reforma el Código, se incorpora al ordenamiento jurídico chileno un sistema de tutela de la generalidad de los derechos fundamentales, es decir, de los que corresponden al trabajador en cuanto tal y de los que le corresponden en cuanto persona ${ }^{4}$. En palabras de Ugarte Cataldo, este es el primer paso del Derecho laboral chileno por tomarse en serio los derechos fundamentales de los

\footnotetext{
${ }^{1}$ La Ley $N^{\circ} 19.759$, publicada en el Diario Oficial el 5 de octubre de 2001, perfeccionó la norma del artículo $2^{\circ}$ del Código del Trabajo, en adelante el Código, que prohibía la discriminación en el ámbito laboral.

${ }^{2}$ Esta disposición fue incorporada como inciso primero del artículo $5^{\circ}$ del Código, por la Ley № 19.759 , publicada en el Diario Oficial el 5 de octubre de 2001, pasando sus hasta entonces incisos primero y segundo a ser el segundo y tercero en dicho artículo.

${ }^{3}$ Disposición incorporada como nuevo inciso segundo del artículo $1^{\circ}$ por la Ley $\mathrm{N}^{\circ} 20.005$, publicada en el Diario Oficial el 18 de marzo de 2005.

${ }^{4}$ En este sentido, se expresa en el Mensaje del Presidente de la República en el que se presenta el proyecto de ley que dio lugar a la Ley № 20.087: "Uno de los planes centrales del proyecto apunta a potenciar la vigencia plena, en el ámbito jurídico-laboral, de los derechos que el trabajador detenta no sólo en cuanto trabajador sino que también en su condición de persona". Biblioteca del Congreso Nacional. Historia de la ley. Ley $N^{\circ}$ 20.087. Sustituye el procedimiento laboral contemplado en el Libro $V$ del Código del Trabajo. 03 de enero de 2006, p. 12. En: http://www.bcn.cl/histley/periodos?p=2006 [visitado el 26/07/2010].
} 
trabajadores que no son específicamente laborales ${ }^{5}$. En efecto, esta ley incorpora al Código del Trabajo (arts. 485 y siguientes) un procedimiento judicial para la tutela de los derechos fundamentales y establece las consecuencias para el caso de contravenirse los mismos ${ }^{6}$.

Por otra parte, una tendencia actualmente extendida en el ámbito empresarial es la denominada descentralización productiva, una de cuyas manifestaciones es la tercerización o externalización laboral ${ }^{7}$. Es en la lógica de la tercerización que se inscriben las figuras jurídicas denominadas subcontratación y suministro de trabajadores. Estas situaciones consisten, en esencia, en que dos empresas se relacionan entre sí bajo las normas del Derecho civil o comercial con miras a que una parte de la actividad productiva de la primera sea cumplida por trabajadores que tienen una relación contractual de carácter laboral con la segunda.

El suministro de trabajadores, que es el fenómeno jurídico de interés para esta investigación, se incorporó al Código mediante la Ley № 20.123, publicada el 16 de octubre de 2006. En lo esencial, esta figura consiste en que un trabajador es contratado por una empresa para prestar servicios para un tercero, de modo que mientras dicha empresa aparece como empleadora, el tercero recibe directamente el servicio personal. Las partes de esta relación triangular serán en adelante denominadas, respectivamente, trabajador suministrado, empresa de servicios transitorios y empresa usuaria ${ }^{8}$.

\footnotetext{
${ }^{5}$ Ugarte Cataldo afirma que el procedimiento de tutela "es el primer paso del orden jurídico laboral por tomar en serio los denominados derechos fundamentales inespecíficos de los trabajadores -derechos constitucionales no propiamente laborales-, comenzando poco a poco a desmontarse lo que podríamos denominar el modelo cerrado de empresa, entendido como un espacio jurídico privado donde la acción de los derechos sólo quedaba restringida al cumplimiento de condiciones laborales y económicas mínimas, para dar paso a un espacio jurídico público, expuesto al efecto expansivo de los derechos fundamentales". UGARTE CATALDO, José Luis, "Tutela laboral de derechos fundamentales y carga de la prueba", Revista de Derecho (Valparaíso) № 33, 2009, p. 216. En: http://www.scielo.cl/scielo. php?script=sci_arttext\&pid=S071868512009000200005 \&lng=es\&nrm=iso [visitado el 08/07/2010].

${ }^{6}$ Ver párrafo $6^{\circ}$, del Capítulo II, del Título I, del Libro V del Código.

${ }^{7} \mathrm{Al}$ respecto, explica Rojas Miño: “La descentralización productiva se plantea principalmente por las nuevas formas de organización de las empresas: de una parte la empresa se reorganiza en entidades jurídicas más pequeñas, manteniendo en todo caso una dirección común, de la otra, se plantea una 'tercerización' de las actividades tanto principales como accesorias de las mismas empresas, en cuanto éstas son contratadas o subcontratadas, o son realizadas por empresas de trabajo temporal o por trabajo a domicilio". Rojas Miño, Irene, "Los desafíos actuales del derecho del trabajo en Chile", Revista lus et Praxis Año 12 № 1, 2006, ver especialmente pp. 242 y 243. En: http://www. scielo.cl/scielo.php?script=sci_arttext\&pid=S071800122006000 100010\&lng=es\&nrm=iso [visitado el 25/08/2010].

${ }^{8}$ Sólo la expresión empresa de servicios transitorios utilizada en este trabajo coincide con la empleada en el Código. Lo que aquí se denomina trabajador suministrado y empresa usuaria son Ilamados, respectivamente, trabajador de servicios transitorios y usuaria por el Código. Se ha preferido la expresión trabajador suministrado, porque existen otros trabajadores que prestan servicios transitorios que no participan de la relación triangular consistente en el suministro de trabajadores (ver artículo 159,
} 
Pues bien, no parece difícil advertir que se pueden producir diversos problemas al relacionar la exigencia de respeto de los derechos fundamentales en el ámbito laboral y la posibilidad de externalizar los servicios mediante el suministro de trabajadores. Uno de ellos consiste en determinar si resulta posible aplicar el procedimiento de tutela a la empresa usuaria de trabajadores suministrados. En este punto conviene advertir que el procedimiento de tutela resulta aplicable en los siguientes casos: vulneración al principio de igualdad de remuneraciones entre hombres y mujeres por igual trabajo (art. 62 bis), atentados contra la libertad sindical (art. 292), prácticas desleales en la negociación colectiva (art. 389) y vulneración de derechos fundamentales (art. 485).

La presente investigación se refiere exclusivamente al último de estos casos, es decir, a la aplicación respecto de la empresa usuaria del procedimiento de tutela en caso que lesione los derechos fundamentales del trabajador suministrado. Así delimitado, el problema en cuestión puede ser expresado mediante la siguiente pregunta: ipuede la empresa usuaria constituirse en sujeto pasivo del procedimiento de tutela por vulnerar derechos fundamentales de trabajadores suministrados por la empresa de servicios transitorios? 9 . A responder dicha pregunta se dedica la presente investigación.

Adviértase que el problema no consiste en determinar si la empresa usuaria debe respetar los derechos fundamentales de los trabajadores suministrados, cuestión expresamente respondida en el art. 183-Y del Código, sino en precisar si le resulta aplicable el procedimiento de tutela.

\section{Importancia del problema planteado}

Determinar la aplicabilidad del procedimiento de tutela a la empresa usuaria de trabajadores suministrados no es, como puede suponerse, una cuestión baladí. Precisamente al contrario, una respuesta afirmativa implica al menos dos consecuencias de especial significación para el sujeto pasivo de este procedimiento. El primero de ellos consiste en que se le imponen importantes cargas procesales relacionadas con la prueba. El segundo se refiere a que el juez puede adoptar severas medidas respecto de este mismo sujeto en caso de confirmar la existencia de lesión a los derechos fundamentales del trabajador.

números 4 y 5, del Código). Y se ha preferido la expresión empresa usuaria, porque parece identificar de manera más precisa al sujeto que utilizará los servicios del trabajador suministrado.

${ }^{9}$ Se trata, por lo demás, de una de las preguntas que poco después del inicio de la vigencia de la Ley № 20.087 se hacía Caamaño Rojo. En efecto, la Ley № 20.123 inició su vigencia el día 14 de enero de 2007, de acuerdo con lo dispuesto en el artículo $2^{\circ}$ transitorio de la misma. El texto de Caamaño Rojo, por su parte, es de 2007 y se puede ver en CaAmaño Rojo, Eduardo, "La ley de subcontratación y la tutela de los derechos fundamentales de los trabajadores de servicios transitorios", Revista lus et Praxis Año 13 № 2, 2007, p. 190. En: http://www.scielo.cl/scielo.php?script=sci_arttext\&pid=S0 71800122007000200008\&lng=es\&nrm=iso [visitado el 11/07/2010]. 
En cuanto a las cargas procesales, el peso de la prueba se ha radicado en el trabajador, lo que confirma la regla general en la materia ${ }^{10}$. Sin embargo, y según ha sentenciado la propia Corte Suprema, en este caso se ha aliviado significativamente la carga probatoria al trabajador ${ }^{11}$. Y ello, como explica Ugarte Cataldo, porque las conductas lesivas de derechos fundamentales se encubren bajo conductas aparentemente lícitas y porque el empleador cuenta con un marcado dominio y control sobre las fuentes probatorias ${ }^{12}$.

De este modo, el procedimiento de tutela dispone que al trabajador le basta aportar antecedentes que constituyan "indicios suficientes" de que se ha producido una vulneración de cualquiera de los derechos fundamentales señalados en el artículo 485 del Código ${ }^{13}$. En tal caso, corresponderá al empleador explicar los fundamentos de su decisión y su proporcionalidad (artículo 493). En consecuencia, no deberá probar que no afectó tales derechos, sino la juridicidad de la medida ${ }^{14}$. Como se puede apreciar, la magnitud de la carga procesal que recae sobre el sujeto pasivo del procedimiento de tutela es evidente.

\footnotetext{
${ }^{10} \mathrm{Al}$ respecto conviene recordar el artículo 1498 del Código Civil, que dispone que incumbe probar la existencia o extinción de las obligaciones al que alega aquélla o éstas.

${ }^{11}$ La Corte Suprema ha sostenido que "esta norma no altera la carga de la prueba, en la medida que impone a quien denuncia la presunta vulneración de derechos fundamentales la obligación de acreditar su aserto, pero ciertamente aliviana dicha carga, al exigir un menor estándar de comprobación, pues bastará justificar 'indicios suficientes', es decir, proporcionar elementos, datos o señales que puedan servir de base para que el acto denunciado pueda presumirse verdadero". Sentencia de la E. Corte Suprema, recurso de unificación de jurisprudencia, 14 de enero de 2010, rol 7023 de 2009, considerando séptimo. En: http://www.pjud.cl/modulos/BusqCausas/BCA_esta402.php?rowdetalle=A AANoPAANAACtgZAAC $\&$ consulta $=100 \&$ causa $=7023 / 2009 \&$ numcua $=1555 \&$ secre $=$ UNICA $[$ visitado el 21/07/2010].

12 UGARTE, "Tutela laboral", cit. nota n. 5, p. 217.

${ }^{13}$ La Corte Suprema ha sentenciado expresamente que la existencia de "indicios suficientes" constituye una carga aligerada que procede no sólo respecto de los derechos fundamentales indicados en el inciso primero del artículo 485 del Código, sino también respecto de las discriminaciones a que se refiere el inciso segundo de la misma disposición. Al respecto ha dispuesto que "sobre la base de las precisiones que anteceden, tratándose de un juicio en que se reclama de un despido discriminatorio o dispuesto en contravención de derechos fundamentales, resultaba plenamente procedente aplicar la prueba indiciaria prevista en el artículo 493 del Código del Trabajo, como ocurrió en el caso en estudio". Y esto en contra de lo señalado en el voto de minoría suscrito por uno de los Ministros de la Cuarta Sala, en el que se postuló que "dicha norma legal al disponer que la prueba indiciaria se aplica a aquellos casos en que se han vulnerado derechos fundamentales, sólo está referida al inciso primero del artículo 485 del Código antes citado, ya que al constituir una forma excepcional de ponderación debe, interpretarse restrictivamente". Sentencia de la E. Corte Suprema, recurso de unificación de jurisprudencia, 14 de enero de 2010, rol 7023 de 2009, considerando undécimo. En: http://www.pjud. $\mathrm{cl} /$ modulos/BusqCausas/BCA_esta402.php? rowdetalle=AAANoPAANAACtgZAAC\&consulta $=100 \& \mathrm{ca}$ usa $=7023 / 2009 \&$ numcua $=1555 \&$ secre $=$ UNICA [visitado el 21/07/2010] .

${ }^{14}$ En este mismo sentido, en el Mensaje que precedió al proyecto de ley que dio origen a la Ley № 20.087, se expresa lo siguiente: "Se produce entonces, una matización de la regla general sobre la carga de la prueba, ya que al trabajador le basta con que de sus alegaciones se desprendan "indicios", es decir, señales o evidencias que den cuenta de un hecho oculto (violación de un derecho fundamental). Es de destacar que en este evento no se exige al empleador la prueba de un hecho negativo
} 
Si el procedimiento de tutela así entendido es procedente respecto del suministro de trabajadores, entonces la empresa usuaria quedará sometida a estas mismas cargas procesales. Esto significa que, si el trabajador suministrado aportó "indicios suficientes" de la existencia de una vulneración de sus derechos fundamentales por la empresa usuaria, esta última no podrá alegar la inexistencia de dicha afectación. Su única opción será justificar la medida denunciada y su proporcionalidad.

A las referidas cargas procesales es necesario agregar las medidas que puede aplicar el juez al sujeto pasivo del procedimiento de tutela. Al respecto resulta necesario distinguir aquellas que puede adoptar durante el procedimiento y aquellas que puede adoptar al dictar sentencia definitiva. Durante el procedimiento debe disponer, de oficio o a petición de parte, el cese del acto impugnado o la suspensión de sus efectos, tan pronto como los antecedentes acompañados al proceso muestren que se trata de lesiones de especial gravedad o que la vulneración pueda causar efectos irreversibles. Esta medida se aplicará bajo apercibimiento de 50 a 100 unidades tributarias mensuales, la que puede repetirse hasta que se cumpla dicha decisión judicial (artículo 492).

Al momento de dictar sentencia definitiva el juez deberá ordenar el cese del acto denunciado o la suspensión de los efectos del mismo. Además, debe determinar las medidas conducentes a la reparación del afectado, entre las que puede incluir las pertinentes indemnizaciones. En tercer lugar, el juez debe velar para que la situación se retrotraiga al estado anterior a la vulneración de los derechos. Por último, deberá aplicar las multas que procedan (artículo 495) $)^{15}$.

Conviene reiterar que todas estas medidas pueden ser adoptadas por el juez en caso de vulneración de los derechos fundamentales del trabajador. Ahora bien, determinar con precisión si todas o sólo algunas de ellas son realmente aplicables a la empresa usuaria es un problema que excede el objetivo de este trabajo. Por ahora basta con constatar que si la empresa usuaria es sujeto pasivo del procedimiento de tutela, entonces, en principio, podría quedar sujeta a estas mismas medidas.

(que no violó el derecho fundamental), sino que pruebe que el acto o conducta empresarial obedeció a una motivación legítima". Biblioteca del Congreso Nacional, Historia de la ley. Ley No 20.087, cit. nota n. 4, p. 26.

${ }^{15} \mathrm{Al}$ respecto, el Mensaje del proyecto de ley que dio origen a la Ley $\mathrm{N}^{\circ} 20.087$ señala lo siguiente: "En el contenido de la sentencia condenatoria, el proyecto apunta a retrotraer la situación al estado inmediatamente anterior de producirse la vulneración denunciada, siendo la nulidad el efecto propio y natural para este tipo de ilícitos. Adicionalmente, la sentencia deberá indicar concretamente las medidas tendientes a obtener la reparación de las consecuencias derivadas de la vulneración constatada, incluyendo la posibilidad de que se imponga el pago de una indemnización". Biblioteca del Congreso Nacional, Historia de la ley. Ley No 20.087, cit. nota n. 4, p. 26. 
Todo lo dicho explica la importancia de esclarecer si la empresa usuaria de trabajadores suministrados puede ser sujeto pasivo del procedimiento de tutela de derechos fundamentales regulado en el Código.

\section{Plan de trabajo}

Para elucidar si la empresa usuaria puede ser sujeto pasivo en el procedimiento de tutela por vulnerar derechos fundamentales de los trabajadores que le han sido suministrados por una empresa de servicios transitorios se pueden seguir diversas vías. La vía escogida en este trabajo consiste en determinar si los requisitos establecidos por el Código para la aplicación del procedimiento de tutela se cumplen respecto de la empresa usuaria.

$\mathrm{Al}$ efecto conviene tener presente que, de acuerdo con lo dispuesto en el artículo 485 del Código, el procedimiento de tutela se aplica (1) respecto de las cuestiones suscitadas en la relación laboral por aplicación de las normas laborales, (2) que afecten ciertos derechos fundamentales de los trabajadores, (3) cuando aquellos derechos resulten lesionados en el ejercicio de las facultades del empleador.

Como se puede advertir, se trata de tres requisitos copulativos que circunscriben el ámbito de aplicación del procedimiento de tutela. En lo que sigue se analizará si se puede considerar que tales requisitos concurren respecto de la empresa usuaria. Este análisis se desarrollará mediante la consideración sucesiva de cada uno de esos requisitos.

\section{LA VULNERACIÓN DEBE PRODUCIRSE EN LA RELACIÓN LABORAL}

De acuerdo con lo recién expresado, el procedimiento de tutela presenta como primer requisito que se trate de cuestiones suscitadas en la relación laboral por aplicación de las normas laborales. Para apreciar la concurrencia de este primer requisito respecto de la empresa usuaria es necesario, en primer lugar, esclarecer el significado de este requisito y, en segundo lugar, determinar si resulta aplicable a la empresa usuaria.

\section{Significado del requisito}

Según se ha expresado, el Código dispone, textualmente, que el procedimiento de tutela se aplica "respecto de cuestiones suscitadas en la relación laboral por aplicación de las normas laborales".

Pues bien, y en primer lugar, la consideración literal de esta disposición carece de sentido. En efecto, la vulneración de derechos fundamentales no puede ser consecuencia de la "aplicación de las normas laborales". Precisamente al contrario, dicha lesión constituye la consecuencia de un hecho totalmente independiente de las normas laborales (por ejemplo, atentar contra la libertad religiosa del trabajador) o que importa una transgresión a las mismas (ejemplo, 
discriminar entre trabajadores). Por tanto, para comprender el significado de este requisito basta considerar su primera parte, esto es, que se trate de una lesión suscitada "en la relación laboral". En esta idea se encuentra la exigencia que debe ser satisfecha para dar por cumplido el primero de los requisitos de aplicación del procedimiento de tutela.

En segundo lugar, conviene tener presente que no era esta la redacción del proyecto originalmente remitido por el Ejecutivo al Congreso Nacional. En dicho proyecto el actual artículo 485 (entonces artículo 502) expresaba que el procedimiento "tiene por objeto tutelar los derechos fundamentales de los trabajadores en el ámbito de las relaciones laborales"16. En consecuencia, el requisito en análisis consistía en que la lesión se produjera "en el ámbito de las relaciones laborales"17.

En tercer lugar, la Dirección del Trabajo ha interpretado este requisito del siguiente modo: "La norma exige que la vulneración tenga lugar en la relación laboral, y por aplicación de las normas laborales, con lo que debe entenderse que sólo se encuentran tuteladas por este procedimiento, los específicos derechos reseñados en la norma cuando son afectados en el ámbito del trabajo, con ocasión del trabajo o como consecuencia del mismo"18.

A lo anterior debe añadirse la siguiente constatación: cuando en el Código se alude de manera genérica a la competencia de los juzgados del trabajo, expresamente se dispone que los mismos conocerán de "las cuestiones suscitadas entre empleadores y trabajadores por aplicación de las normas laborales" (art. 420, letra a). Por el contrario, la aplicación del procedimiento de tutela no exige que la cuestión se haya suscitado entre trabajador y empleador, es decir, entre las partes directas de la relación laboral. La importancia de esta diferencia será destacada de inmediato.

A partir de todo lo expresado, resulta posible sostener que el Código no exige que las cuestiones se produzcan entre el empleador y el trabajador de una determinada relación laboral. En efecto, y por una parte, ni el tenor literal del artículo 485, ni el proyecto enviado por el Ejecutivo, ni la interpretación ofrecida por la Dirección del Trabajo exigen que la cuestión se suscite entre las partes del contrato de trabajo. Sólo exigen que se produzcan "en la relación

\footnotetext{
${ }^{16}$ Biblioteca del Congreso Nacional, Historia de la ley. Ley No 20.087, cit. nota n. 4, p. 47.

${ }^{17}$ Fue a partir de una indicación del senador Boeninger que se sustituyó la redacción propuesta por el Ejecutivo para esta parte de la disposición por la actualmente incluida en el Código. Ver Biblioteca del Congreso Nacional, Historia de la ley. Ley N²0.087, cit. nota n. 4, p. 643.

${ }^{18}$ Dirección del Trabajo. Orden de servicio № 9, de 31 de diciembre de 2008. "Imparte instrucciones sobre procedimiento administrativo en caso de denuncia por vulneración de derechos fundamentales, en el marco de la Ley $\mathrm{N}^{\circ}$ 20.087, que incorpora procedimiento de tutela laboral, aplicable a las regiones en la cuales ha entrado o entrará en vigencia la reforma procesal laboral incorporada por la Ley No 20.087". En: http://www.dt.gob.cl/transparencia/Orden_Servicio_09_31-12-08.doc [visitado el 10/08/2010].
} 
laboral", "en el ámbito de las relaciones laborales" y "en el ámbito, con ocasión o a consecuencia del trabajo", respectivamente. Por otra parte, la consideración de la disposición que determina la competencia de los juzgados del trabajo permite afirmar que, si se hubiera deseado que las cuestiones conducentes a la aplicación del procedimiento de tutela se suscitaran entre las partes directas de la relación laboral, así se habría expresado.

\section{Cumplimiento del requisito en el suministro de trabajadores}

En lo que sigue se intentará evidenciar si respecto del suministro de trabajadores se cumple el requisito consistente en que la lesión del derecho fundamental se debe producir en la relación laboral. Al efecto es necesario explicitar, en forma previa, cuáles son las partes en el suministro de trabajadores. Por ello, a continuación se tratará este último asunto para pasar luego al primero de ellos.

\subsection{Las partes en el suministro de trabajadores}

El suministro de trabajadores se ha regulado en los artículos $183 \mathrm{~F}$ y siguientes del Código. En estas disposiciones se distingue a la empresa de servicios transitorios, a la empresa usuaria de los servicios de los trabajadores suministrados por la primera y a los trabajadores suministrados.

La empresa de servicios transitorios es definida en el artículo $183 \mathrm{~F}$, letra a), del Código como: Toda persona jurídica, inscrita en el registro respectivo, que tenga por objeto social exclusivo poner a disposición de terceros denominados para estos efectos empresas usuarias, trabajadores para cumplir en estas últimas, tareas de carácter transitorio u ocasional, como asimismo la selección, capacitación y formación de trabajadores, así como otras actividades afines en el ámbito de los recursos humanos. Tanto Claudio Palavecino ${ }^{19}$, como Luis Lizama y José Ugarte ${ }^{20}$ coinciden en destacar que el giro de la empresa de servicios transitorios es el suministro de trabajadores, es decir, la puesta a disposición de otra empresa, y que retienen la calidad de empleadores respecto de tales trabajadores.

\footnotetext{
${ }^{19}$ Palavecino define a la empresa de servicios transitorios como "aquélla cuya actividad consiste en poner a disposición de otra empresa, con carácter temporal, trabajadores por ella contratados respecto de los cuales ostenta la condición de empleador, a través de un contrato civil o mercantil de puesta a disposición por un tiempo determinado y por un precio". Ver PALAVECINO, Claudio, Subcontratación: Régimen Jurídico del Trabajo Subcontratado y de suministro de personal, Jurídica de Chile, Santiago de Chile, 2006, p. 83.

${ }^{20}$ Lizama Portal y Ugarte Cataldo explican que, para que se trate de un caso de suministro de trabajadores es necesario que concurran ciertas condiciones fundamentales, entre las cuales se incluye que se considere "como empleadora a la empresa suministradora, y no a la que recibe los servicios". Ver Lizama Portal, Luis; Ugarte Cataldo, José, Subcontratación y Suministro de Trabajadores, LexisNexis, Santiago de Chile, 2007, pp. 5 y 6.
} 
La empresa usuaria es definida por el artículo $183 \mathrm{~F}$, letra b), del siguiente modo: Toda persona natural o jurídica que contrata con una empresa de servicios transitorios, la puesta a disposición de trabajadores para realizar labores o tareas transitorias u ocasionales, cuando concurra alguna de las circunstancias enumeradas en el artículo 183-Ñ de este Código. La doctrina coincide en destacar que la empresa usuaria es la que efectivamente utiliza los servicios de los trabajadores contratados por la empresa de servicios transitorios.

El trabajador suministrado es definido en la letra c) del artículo 183 F. Se entiende por tal a todo aquel que ha convenido un contrato de trabajo con una empresa de servicios transitorios para prestar servicios transitorios u ocasionales en una o más usuarias de aquélla, de acuerdo a las disposiciones del propio Código. En este punto conviene destacar que el prestar servicios esencialmente transitorios u ocasionales en la empresa usuaria no obsta, como es evidente, que el trabajador pueda tener y habitualmente tenga un contrato indefinido con la empresa de servicios transitorios.

\subsection{La relación laboral en el suministro de trabajadores}

En el suministro de trabajadores se producen dos clases de relaciones contractuales. La primera relación, de carácter civil, se produce entre la empresa de servicios transitorios y la empresa usuaria, y consiste en el contrato de puesta a disposición de trabajadores transitorios (art. 183-N). La segunda relación contractual, de carácter laboral, se produce entre la empresa de servicios transitorios y el trabajador suministrado (art. 183-R).

Adviértase que el Código ha eludido calificar la relación existente entre la empresa usuaria y el trabajador suministrado. Al mismo tiempo, no se puede desconocer que la regulación vigente ha incorporado una serie de prescripciones propias del ámbito laboral al regular la relación entre la primera y este último. Así, por ejemplo, la Dirección del Trabajo puede fiscalizar el cumplimiento de las normas laborales bajo el régimen de suministro de trabajadores en la empresa usuaria, y no sólo en la empresa de servicios transitorios (art. 183-G). Del mismo modo, las cuestiones suscitadas entre las empresas usuarias y los trabajadores suministrados son de competencia de los juzgados del trabajo, y no sólo las que se produzcan entre esos trabajadores y las empresas de suministro de trabajadores (art. 183-H). En fin, a la empresa usuaria corresponde cumplir las normas relativas a seguridad e higiene en el trabajo, incluyendo las relativas al seguro contra accidentes del trabajo y enfermedades profesionales (art. $183 \mathrm{AB}$ ).

Sin embargo, no resulta posible sostener que entre la empresa usuaria y el trabajador suministrado exista un vínculo contractual de carácter laboral. Como 
destaca Ugarte Cataldo, es efectivo que el mando y la dependencia corresponde a dicha empresa y no a la empresa de suministro de trabajadores. No obstante, y en palabras del mismo autor, la ley altera las reglas generales, a cambio de una regulación que garantice los derechos de los trabajadores ${ }^{21}$. Por tanto, y en definitiva, entre la empresa usuaria y el trabajador suministrado no existe una relación laboral.

Ahora bien, lo recién afirmado no conduce a sostener la inaplicabilidad del procedimiento de tutela en contra de la empresa usuaria en caso que lesione los derechos fundamentales de los trabajadores suministrados. En efecto, y de un lado, no es necesario que la cuestión se suscite entre las partes de un determinado contrato de trabajo. Al respecto se debe recordar que, de acuerdo con lo dispuesto en el artículo 485 del Código, en el proyecto que dio lugar a la Ley $N^{\circ} 20.087$ y en la interpretación administrativa más arriba citada, basta que la vulneración se produzca en el ámbito, con ocasión o a causa de la relación laboral.

De otro lado, la eventual lesión de derechos fundamentales de un trabajador suministrado por parte de la empresa usuaria se produce precisamente en la relación laboral, en el sentido de en el ámbito laboral o con ocasión de la relación laboral. En efecto, la empresa usuaria utiliza los servicios del trabajador suministrado, porque entre éste y la empresa de servicios transitorios existe un vínculo contractual regulado por el Derecho del trabajo. De este modo, las cuestiones suscitadas entre la empresa usuaria y el trabajador suministrado se dan en el ámbito o con ocasión de la relación laboral existente entre este último y la empresa de servicios transitorios.

En definitiva, resulta posible afirmar que la relación entre la empresa usuaria y el trabajador suministrado se da en la relación laboral, esto es, en el ámbito o con ocasión de la relación laboral. Por tanto, respecto de la empresa usuaria se cumple el primero de los requisitos de aplicación del procedimiento de tutela.

\section{LESIÓN DE DERECHOS FUNDAMENTALES}

El segundo requisito para la aplicación del procedimiento de tutela es que se lesione alguno de los derechos fundamentales del trabajador expresados en el art. 485 del Código. Para verificar si este requisito concurre respecto de la empresa usuaria es necesario revisar, en primer lugar, en qué consiste este requisito. Y, en segundo lugar, si este requisito se cumple respecto de la empresa usuaria.

\footnotetext{
${ }^{21}$ UGARTE CATALDO, José Luis, "Sobre relaciones laborales triangulares: La subcontratación y el suministro de trabajadores", Revista lus et Praxis Año 12 № 1, 2006, ver especialmente pp. 22 a 24. En: http://www.scielo.cl/scielo.php?script=sci_arttext\&pid=S0718-00122006000100002\&lng=es\&nrm=iso [visitado el 16/08/2010].
} 


\section{Significado del requisito}

El tenor del artículo 485 del Código permite advertir que el procedimiento de tutela sólo ampara ciertos derechos fundamentales y que, entre ellos, se pueden distinguir dos categorías. Esas categorías se refieren a derechos fundamentales que son específicos del ámbito laboral y derechos fundamentales que no son específicamente del ámbito laboral, pero que igualmente pueden ser afectados durante dicha prestación de servicios. Estas dos categorías serán aquí denominadas derechos fundamentales específicos y derechos fundamentales inespecíficos, respectivamente.

Los derechos fundamentales específicos respecto de los cuales resulta aplicable el procedimiento de tutela son (1) el derecho a la libertad de trabajo, (2) el derecho a la libre contratación, (3) el derecho a la libre afiliación a cualquier organización o entidad, (4) el derecho a la libre desafiliación a cualquier organización o entidad y (5) el derecho a no ser discriminado ${ }^{22}$, aunque este último con ciertas limitaciones ${ }^{23}$.

Los derechos fundamentales inespecíficos que caen bajo el procedimiento de tutela son (1) los derechos a la vida, a la integridad física y a la integridad síquica, (2) los derechos al respeto y protección de la vida privada y de la honra del trabajador y su familia, (3) el derecho a la inviolabilidad de toda forma de

\footnotetext{
${ }^{22}$ Curiosamente el Código no incluye el derecho a no ser discriminado entre los que, en el inciso primero del artículo 485, denomina derechos fundamentales. En su lugar, prescribe que el procedimiento de tutela procede respecto de los actos discriminatorios a que se refiere el artículo $2^{\circ}$ del mismo Código. Sin embargo, resulta posible sostener que las disposiciones pertinentes de este artículo, esto es, los incisos tercero a séptimo, son derechos fundamentales. En primer lugar, porque el artículo 489 del Código expresamente otorga esta calificación a los derechos aludidos en el inciso segundo del artículo 485. Y en segundo lugar, porque esos mismos derechos constituyen una especificación, en el nivel legal, del derecho fundamental conferido por el artículo 19, número 16, inciso tercero, de la Constitución, que prohíbe las discriminaciones en el ámbito laboral. En el mismo sentido, textualmente se dispone en el considerando décimo de la sentencia de la E. Corte Suprema, recurso de unificación de jurisprudencia, 14 de enero de 2010, rol 7023 de 2009, En: http://www.pjud.cl/modulos/BusqCausas/BCA_esta402.ph p? rowdetalle $=A A A N o P A A N A A C t g Z A A C \&$ consulta $=100 \&$ causa $=7023 / 2009 \&$ numcua $=1555 \&$ secre $=U$ NICA [visitado el 21/07/2010], que: "En consecuencia, no hay razón legal que permita dejar de aplicar la norma del artículo 493, cuando se trata del procedimiento de tutela laboral por causa de despido discriminatorio, tanto más si se considera que las motivaciones de esta clase de despido violentan sin duda derechos fundamentales que la ley ha procurado tutelar, desde que atentan contra la igualdad de oportunidades frente al empleo". De este modo, a partir de lo dispuesto en la Constitución y en el Código, resulta posible afirmar que constituye vulneración al derecho fundamental a no ser discriminado toda distinción, exclusión o preferencia que se basan en cualquier circunstancia que no sean la idoneidad o la capacidad, entendiéndose que las calificaciones exigidas para un empleo permiten evaluar precisamente esa capacidad o idoneidad.

${ }^{23}$ El propio Código dispone (art. 485, inciso segundo, con relación al artículo $2^{\circ}$, inciso sexto) que no se incluyen en el procedimiento de tutela los actos de discriminación realizados en las ofertas de trabajo formuladas directamente por los empleadores o a través de terceros y por cualquier medio. Eso significa que la ley ha excluido las discriminaciones laborales que tienen carácter precontractual.
} 
comunicación privada, (4) los derechos a la libertad de conciencia, a la manifestación de todas las creencias y al ejercicio libre de todos los cultos, y (5) el derecho a la libertad de emitir opinión y de informar.

Ahora bien, y como expresa Gajardo Harboe, los acuerdos de los diversos sectores involucrados en la tramitación parlamentaria hizo necesario que el procedimiento de tutela quedara limitado a ciertos derechos fundamentales y no a todos ellos ${ }^{24}$. Con esta enumeración, expresa Caamaño Rojo, se han dejado de lado algunos derechos fundamentales esenciales para que el suministro de trabajadores se verifique en condiciones de equidad, de plena protección social y de evitar la precarización de esta clase de empleo: la igualdad de trato del trabajador transitorio respecto del trabajador permanente de la empresa usuaria y la libertad sindical ${ }^{25}$. Sin perjuicio de compartir lo afirmado por Gajardo Harboe y por Caamaño Rojo, resulta necesario advertir que esta limitación no es tan radical como aparece de la sola lectura de la disposición en análisis.

Como explica Alexy, los derechos fundamentales son conferidos por normas iusfundamentales directamente estatuidas en el texto constitucional. Las normas iusfundamentales directamente estatuidas son aquellas que se expresan en las disposiciones incluidas en el texto constitucional ${ }^{26}$. Así, por ejemplo, el derecho fundamental a la vida ha sido conferido por una norma directamente estatuida en la Constitución, pues se incluye en el texto del artículo 19, número 1 , de la misma.

Sin embargo, y siguiendo nuevamente a Alexy, los derechos fundamentales también pueden ser conferidos por normas iusfundamentales adscritas a las directamente estatuidas. Las normas iusfundamentales adscritas son las normas de precisión de las directamente estatuidas. En otras palabras, son prescripciones que especifican el significado de las normas expresadas en el texto constitucional. En consecuencia, las normas iusfundamentales adscritas, que aquí llamaremos de precisión, no se encuentran directamente en el texto constitucional ${ }^{27}$.

${ }^{24}$ Gajardo Harboe, María Cristina, "Nuevo procedimiento de tutela laboral: Los derechos protegidos. El derecho a la vida y a la integridad física y síquica de la persona", Actualidad Laboral, enero y febrero, 2009, p. 5. En: http://www.derecho.uchile.cl/profesores/mengod/actualidad_doc/ACTUALIDAD\%20 LABORAL \%20ENERO\%20Y\%20FEBRERO\%202009.doc [visitado el 17/08/2010].

${ }^{25}$ CaAmaño, "La ley de subcontratación", cit. nota n. 9, p. 185.

${ }^{26}$ Ver Alexy, Robert, Teoría de los derechos fundamentales. Centro de Estudios Políticos y Constitucionales, Madrid, 2001, especialmente p. 65.

27 Alexy plantea el problema de las normas de precisión del siguiente modo: "De acuerdo con las definiciones provisorias que se acaban de formular, normas de derecho fundamental son sólo aquellas que son expresadas directamente por enunciados de la LF (disposiciones de derecho fundamental). Cabe preguntar si esta definición no es demasiado estrecha". Luego fundamenta la admisibilidad de las normas de precisión, para concluir sosteniendo lo siguiente: "Las normas de derecho fundamental pueden, por ello, dividirse en dos grupos: en las normas de derecho fundamental directamente esta- 
Las normas iusfundamentales de precisión tienen como fuente, entre otras, a la jurisprudencia. Ello se debe a que, al interpretar las disposiciones constitucionales para aplicarlas a casos concretos, inevitablemente especifican el significado de las genéricas disposiciones constitucionales. Así, por ejemplo, la Corte de Apelaciones de Valdivia ha sentenciado que el acoso moral en el ámbito laboral constituye un atentado a los derechos fundamentales a la integridad física y síquica ${ }^{28}$. Esto significa que el derecho a no ser acosado moralmente en el contexto de una relación laboral constituye una especificación de estos derechos del artículo 19, número 1, de la Constitución.

Pero así como las decisiones judiciales confieren derechos fundamentales mediante normas iusfundamentales de precisión, también niegan la existencia de determinados derechos fundamentales mediante el rechazo de normas iusfundamentales de precisión que supuestamente los confieren. Así, por ejemplo, la Corte de Apelaciones de Valparaíso dispuso que si el empleador firma o fotografía una marcha sindical en la que participan sus trabajadores, no vulnera el derecho fundamental a la libertad de expresión de estos últimos ${ }^{29}$.

Por cierto no interesa debatir aquí si los jueces deben crear normas constitucionales. En palabras de De Asís, en los hechos los jueces sí crean Derecho ${ }^{30}$.

tuidas por la Constitución y las normas de derecho fundamental a ellas adscriptas". Ver AleXY, Teoría, cit. nota n. 26 , pp. 66 y 70.

${ }^{28}$ En lo pertinente, la Corte de Apelaciones de Valdivia sentenció lo siguiente: "Resulta de estos antecedentes que en la unidad laboral de Aseo y Ornato de la I. Municipalidad de Valdivia, donde trabaja la recurrente, hay un ambiente ingrato general con los trabajadores creado por la actitud del señor Arellano, su JEFE, y mantenido a través del tiempo. Perjudicada con esto en su salud es la señora Ramis". Y en cuanto a la necesidad de tutelar el derecho conferido en el artículo 19, número 1, de la Constitución, añade: "La Constitución de la República asegura a todas las personas el derecho a la vida y a la integridad física y psíquica de las personas y, en resguardo de esa garantía, es necesario tomar medidas para poner término a dicho ambiente laboral". Sentencia de la I. Corte de Apelaciones de Valdivia, acoge recurso de protección, 6 de septiembre de 2006, rol 665 de 2006, considerandos duodécimo y decimotercero. En: http://productos.legalpublishing.cl/NXT/publishing.dIl/A_Juridica/ CL_JOLLOL/CL_LSJ00/CL_LSJ06/jad/jad-33?fn=document-frame.htm $\$ f=$ templates $\$ 3.0$. [visitado el 28/07/2010].

${ }^{29}$ En la oportunidad la Corte de Apelaciones de Valdivia textualmente dispuso en el considerando decimocuarto: "Que si bien está acreditado que el Director del Mercurio, señor Toro, se encontraba en el balcón del edificio del Diario El Mercurio con una cámara con actitudes de estar filmando o fotografiando los hechos que ocurrieran en ese momento, el día 16 de abril de este año, sin embargo no se aprecia de qué manera tal conducta pueda constituir una vulneración real, efectiva del derecho constitucional de la libre expresión consagrada en el № 12 del artículo 19 de la Constitución Política de la República". Sentencia de la I. Corte de Apelaciones de Valparaíso, recurso de nulidad, 9 de noviembre de 2009, rol 373-2009. En: http://www.pjud.cl/modulos/BusqCausas/BCA_esta402.php?row detalle=AAANoPAANAACuogAAE \&consulta $=100 \&$ causa $=373 / 2009 \&$ numcua $=41337 \&$ secre $=$ REFOR MA LABORAL [visitado el 28/07/2010].

${ }^{30}$ De Asís Roig expresa al respecto: "A lo largo del análisis que hemos efectuado de distintos modelos de argumentación y en el esquema que acabamos de proponer se puede fácilmente observar cómo el 
En el mismo sentido se pronuncian, entre otros, Peces-Barba Martínez ${ }^{31}$, Rivera Santibáñez ${ }^{32}$, García Figueroa ${ }^{33}$ y Ruiz Molleda ${ }^{34}$. Esta función de precisar el significado de las normas iusfundamentales directamente estatuidas es, por lo demás, imprescindible. En efecto, sólo de ese modo es posible que tales normas puedan resolver los casos sometidos a la decisión judicial ${ }^{35}$.

Todo lo dicho permite determinar a qué derechos fundamentales se extiende la aplicación del procedimiento de tutela regulado en el Código. Aquél sólo procede respecto de los derechos fundamentales específicos e inespecíficos referidos en las normas iusfundamentales, directamente estatuidas en las disposiciones constitucionales citadas en el artículo 485. No obstante, el procedimiento de tutela resulta aplicable, además, a los derechos fundamentales otorgados por

juzgador crea o establece diferentes enunciados normativos". De Asís Roı,, Rafael, Jueces y normas. La decisión judicial desde el ordenamiento, Marcial Pons, Madrid, 1995, p. 219.

${ }^{31}$ En este sentido expresa Peces-Barba Martínez que "podemos distinguir los derechos según su forma de incorporación al Derecho positivo: por el Derecho legal (Constitución, Ley) y por el Derecho judicial (jurisprudencia de los tribunales). El primer supuesto se sitúa más en el ámbito del Derecho continental y el segundo en el Derecho anglosajón, aunque hoy en día la integración de ambos criterios es la regla más general". Peces-Barba Martínez, Gregorio, Derecho y derechos fundamentales. Centro de Estudios Políticos y Constitucionales, Madrid, 1993, pp. 344 y 345.

32 Rivera Santibáñez destaca que "las resoluciones emitidas en la jurisdicción constitucional adquieren una trascendental importancia. A través de ellas se da concreción normativa a las cláusulas abstractas de la Constitución, convirtiendo los derechos políticos y abstractos en derechos jurídicos y concretos; asimismo se desarrollan las normas generales de la Ley Fundamental, en cuyo cometido se crea Derecho extrayendo innumerables normas implícitas, no expresas, contenidas en la Constitución, que sean idóneas para regular cualquier aspecto de la vida social y política. De ahí que, en el constitucionalismo contemporáneo se ha cambiado la concepción clásica sobre la función de la Jurisdicción Constitucional, pues frente a la visión kelseniana del 'legislador negativo' hoy se la concibe en la función 'creadora del Derecho'. Rivera SantibáÑEZ, José Antonio, "Los efectos de las sentencias constitucionales en el ordenamiento jurídico interno", Estudios Constitucionales Año $4 \mathrm{~N}^{\circ}$ 2, Centro de Estudios Constitucionales, 2006, pp. 585 y 586. En: http://www.cecoch.cl/htm/revista/docs/estudiosconst/4n_2_2006/23.pdf. ISSN 0718-0195 [visitado 20/11/2008].

${ }^{33}$ En este sentido García Figueroa afirma que "los derechos fundamentales se concretan jurisprudencialmente". Ver García Figueroa, Alfonso, "La incidencia de la derrotabilidad de los principios iusfundamentales sobre el concepto de Derecho", Diritto \& questioni publiche, p. 199. En: http://www. dirittoequestionipubbliche.org/D_Q-3/studi/D_Q-3_studi_Figueroa.pdf [visitado el 22/11/2008].

${ }^{34}$ Ruiz Molleda defiende las potestades del Tribunal Constitucional como creador de nuevas normas en su actividad interpretativa y ofrece algunas citas a favor de esta perspectiva. Ver RuIz MolLEDA, Juan Carlos, "En defensa del Tribunal Constitucional: 10 razones jurídicas para resguardar sus potestades interpretativas", Justicia Viva, Lima, 2006, especialmente pp. 14 y 15. En: http://www.justiciaviva.org. pe/publica/10_razones.pdf [visitado el 5/11/2007].

35 Una respuesta afirmativa en lo relativo a si la jurisprudencia crea normas jurídicas no conduce de manera necesaria a responder en igual sentido el problema de la sumisión al precedente por parte de los jueces. La relación entre ambos se encuentra en que este último problema sólo surge si se cuenta con una respuesta afirmativa frente al primero. Por cierto, no resulta pertinente extenderse aquí sobre el alcance de tales cuestiones. 
normas iusfundamentales de precisión de las normas iusfundamentales directamente estatuidas en las disposiciones constitucionales señaladas en el artículo 485. En consecuencia, y en síntesis, los derechos fundamentales protegidos por el procedimiento de tutela son tanto los específicos como los inespecíficos contemplados en ambas clases de normas iusfundamentales.

Por último, resulta imprescindible destacar que los derechos fundamentales de los trabajadores se entienden lesionados bajo dos grandes supuestos. En primer lugar, si el pleno ejercicio de los derechos fundamentales resulta limitado sin justificación suficiente, en forma arbitraria, en forma desproporcionada o sin respeto a su contenido esencial como consecuencia del ejercicio de las facultades que la ley le reconoce al empleador. En segundo lugar, si el pleno ejercicio de los derechos fundamentales es consecuencia de represalias ejercidas en razón o como consecuencia de la labor fiscalizadora de la Dirección del Trabajo o por el ejercicio de acciones judiciales (art. 485 del Código).

\section{Lesión de derechos fundamentales por la empresa usuaria}

Una vez identificados los derechos fundamentales amparados por el procedimiento de tutela, corresponde determinar si los mismos pueden ser lesionados por la empresa usuaria.

Que los derechos fundamentales del trabajador pueden ser vulnerados por su empleador es una cuestión fuera de toda controversia. Por ello, el Derecho legislado ha dispuesto de manera general que el ejercicio de las facultades que la ley reconoce al empleador tiene como límite el respeto de las garantías constitucionales de los trabajadores, en especial cuando afectare la intimidad, la vida privada o la honra de éstos (art. $5^{\circ}$ del Código). Del mismo modo, ha precisado que el empleador debe mantener reserva de toda la información y datos privados del trabajador a que tenga acceso con ocasión de la relación laboral (art. 154 bis).

Según se expresó al inicio de este trabajo, igualmente indudable es que los derechos fundamentales del trabajador suministrado pueden ser lesionados por la empresa usuaria en la que se desempeña. El Código lo reconoce expresamente en el art. 183-Y, al prescribir que el ejercicio de las facultades que la ley reconoce a la empresa usuaria respecto del trabajador tiene como límite el respeto de los derechos fundamentales de este último. Y añade que esta disposición opera "en especial" cuando pudieren afectar la intimidad, la vida privada o la honra del mismo, lo que muestra el carácter meramente referencial de estas menciones. Además, la misma disposición precisa en el inciso segundo que la empresa usuaria debe mantener reserva de toda la información y datos privados del trabajador a que tenga acceso con ocasión de la relación 
labora ${ }^{36}$. Como expresa Caamaño Rojo, la inclusión de esta disposición evita todo riesgo interpretativo respecto de la obligación de la empresa usuaria de respetar los derechos fundamentales del trabajador suministrado ${ }^{37}$.

Pero el cumplimiento del segundo de los requisitos de aplicación del procedimiento de tutela respecto de la empresa usuaria no sólo deriva de lo dispuesto en el art. 183-Y del Código. Junto con ello, dicha empresa se encuentra fácticamente en condiciones de afectar la mayoría, si no todos, los derechos fundamentales del trabajador suministrado que se enumeran en el art. 485 del Código. Esto se debe al poder de mando que ostenta la primera sobre este último y que le confiere facultades propias del empleador respecto del mismo, asunto sobre el que se volverá más abajo.

Ahora bien, la empresa usuaria se encuentra en condiciones jurídicas y fácticas de lesionar tanto los derechos fundamentales específicos como los inespecíficos del art. 485. En efecto, y en cuanto a los primeros, no resulta difícil imaginar situaciones de contravención a los derechos a la libre afiliación o desafiliación a cualquier organización o entidad y el derecho a no ser discriminado. La cuestión parece todavía más sencilla respecto de los derechos inespecíficos, pues la empresa usuaria puede vulnerar los derechos a la vida, a la integridad física y síquica, a la inviolabilidad de las comunicaciones privadas, a la libertad religiosa y a la libertad de emitir opinión, por mencionar sólo algunos.

Del mismo modo, la empresa usuaria se encuentra limitada no sólo por los derechos fundamentales conferidos por las normas directamente estatuidas que se citan en el art. 485 del Código. Al igual que cualquier otro sujeto, se encuentra también sometido a las normas de precisión de esas mismas normas que la jurisprudencia genere. Al menos de modo referencial si no ha sido parte

\footnotetext{
${ }^{36}$ Como se puede advertir, lo dispuesto en el art. 183-Y constituye una reiteración de los artículos $5^{\circ}$ y 154 bis del Código del Trabajo, pero ahora en lo relativo a la empresa usuaria. Así lo destacaron, por lo demás, los representantes del Ejecutivo en la tramitación parlamentaria del proyecto que dio origen a la Ley No 20.123. Ver Biblioteca del Congreso Nacional. Historia de la ley. Ley No 20.123. Regula trabajo en régimen de subcontratación, el funcionamiento de las Empresas de Servicios Transitorios y el contrato de trabajo de servicios transitorios. 16 de octubre de 2006, p. 169. En: http:// www.bcn.cl/histley/periodos?p=2006 [visitado el 26/07/2010].

${ }^{37}$ En palabras de Caamaño Rojo, "frente a la configuración de una relación de carácter triangular, que es propia y definidora del suministro de trabajadores, la explicitación del debido respeto de los derechos fundamentales debido por la usuaria al trabajador transitorio viene a evitar algunos problemas interpretativos mayores acerca de su real grado de eficacia, dado que la usuaria no es verdaderamente empleadora, con lo cual se excluyen sin más las interpretaciones literales -tan queridas en nuestro medio nacional- que habrían podido hacerse del artículo $5^{\circ}$ inciso 1 del CdT y que habrían podido significar una exclusión de la ciudadanía laboral en el ámbito de los servicios transitorios". CaAmaño, "La ley de subcontratación", cit. nota n. 9, p. 178.
} 
del proceso en que se ha creado dicha norma de precisión ${ }^{38}$, o de modo vinculante en caso contrario ${ }^{39}$.

Por tanto, y en definitiva, la empresa usuaria se encuentra en condiciones jurídicas y fácticas de lesionar los derechos fundamentales indicados en el art. 485 del Código. En consecuencia, a su respecto se cumple el segundo de los requisitos de aplicación del procedimiento de tutela.

\section{LESIÓN COMO CONSECUENCIA DEL EJERCICIO}

\section{DE FACULTADES DEL EMPLEADOR}

La aplicación del procedimiento de tutela presenta como tercer requisito que los derechos fundamentales resulten lesionados en el ejercicio de las facultades del empleador (art. 485). Al igual que en el caso de los dos requisitos anteriores, a continuación se precisará el significado de esta exigencia, para analizar luego su procedencia respecto de la empresa usuaria.

\section{Significado del requisito}

La clave de comprensión del requisito consistente en que la lesión de derechos fundamentales debe provenir del ejercicio de las facultades del empleador se encuentra precisamente en el ejercicio de tales facultades. Ello se debe, como ha expresado la Corte Suprema, a que las materias sometidas al procedimiento de tutela envuelven conflictos en que se enfrenta el ejercicio de la potestad de dirección y mando del empleador y el respeto de los derechos fundamentales de los dependientes ${ }^{40}$. En consecuencia, resulta imprescindible precisar, por una

\footnotetext{
${ }^{38}$ Si la empresa usuaria no ha sido parte del proceso en el que se ha creado una norma iusfundamental de precisión, la vinculación a esta decisión es al menos referencial en atención al efecto relativo de las sentencias a que se refiere el art. $3^{\circ}$ del Código Civil. Con todo, se puede decir que también podría ser vinculante si se consideran las posibilidades normativas que confiere el recurso de unificación de doctrina establecido en el art. 483 del Código, cuestión sobre la cual no resulta pertinente extenderse en este trabajo.

${ }^{39} \mathrm{Si}$ la empresa usuaria ha sido parte del proceso en el que se ha generado la norma iusfundamental de precisión, entonces se encuentra sometida a dicha norma. En efecto, y según lo dispuesto en el art. $3^{\circ}$ del Código Civil, las sentencias tienen fuerza obligatoria respecto de las causas en que actualmente se pronunciaren, esto es, respecto de las partes involucradas por la decisión. Aunque el alcance de esta disposición resulta discutible, lo dicho resulta suficiente para efectos del presente trabajo.

${ }^{40} \mathrm{Al}$ respecto expresó la Corte Suprema que las materias conocidas a través del nuevo procedimiento de tutela "participan de similar naturaleza, en cuanto envuelven conflictos en que se enfrenta el ejercicio de la potestad de dirección y mando de parte del empleador, y el respeto de los derechos fundamentales de sus dependientes, lo que justifica o explica la existencia de un juicio especial, apto para dar pronta y eficaz protección a quien justifique la vulneración denunciada". Sentencia de la E. Corte Suprema, recurso de unificación de jurisprudencia, 14 de enero de 2010, rol 7023 de 2009, considerando quinto. En: http://www.pjud.cl/modulos/BusqCausas/BCA_esta402.php?rowdetalle=AAANoPAANAACtgZAAC $\&$ consulta $=100 \&$ causa $=7023 / 2009 \&$ numcua $=1555 \&$ secre $=$ UNICA [visitado el 21/07/2010]
} 
parte, cuáles son esas facultades y, por otra, quiénes las detentan. Esto permitirá determinar respecto de quiénes resulta aplicable el procedimiento de tutela.

\subsection{Alcance de las facultades del empleador}

Como expresa Ackerman, la relación laboral entre un empleador y un trabajador aislado es, ante todo, una relación de poder, una relación entre un detentador del poder y quien no tiene poder alguno. En este sentido, añade el autor, "la inevitable sumisión a los poderes del empleador que implica el vínculo laboral dependiente, no es compatible con el acuerdo libre de voluntades y el intercambio de concesiones recíprocas que supone un contrato" ${ }^{\prime 41}$ civil, se podría precisar.

La "situación de poder" a que se refiere Ackerman está constituida por un conjunto de atribuciones o facultades a través de las cuales el empleador "concretará la prestación debida por el trabajador y el modo de desempeñarla a fin de que sea llevada a buen término la actividad económica prevista" ${ }^{\prime 2}$. Este conjunto de facultades, que Thayer y Novoa denominan "facultad de mando" 43 , se pueden ordenar en dos grandes ámbitos: el poder de dirección y el poder disciplinario.

En general, el poder de dirección consiste en organizar el conjunto de medios personales, materiales e inmateriales para el logro de los fines económicos, sociales, culturales o benéficos estatuidos para la empresa ${ }^{44}$. En lo relativo a los trabajadores, y siguiendo ahora a Caamaño Rojo, dicho poder incluye determinar el lugar, tiempo y forma de la prestación de servicios ${ }^{45}$. Esto se traduce,

${ }^{41}$ AcKerman, Mario E., "Contrato de servicios y contrato de trabajo. La protección de la persona en las fronteras del Derecho del trabajo", Revista Latinoamericana de Derecho Año IV, No s. 7-8, 2007, pp. 4 a 6. En: http://www.juridicas.unam.mx/publica/rev/indice.htm?r=revlad\&n=7. [visitado el 18/08/2010].

${ }^{42}$ Morato García, Rosa María, Derecho de resistencia y ejercicio irregular del poder de dirección. Especial referencia a la autotutela individual en situaciones de riesgo grave e inminente, Tesis para optar al grado de Doctor, Universidad de Salamanca, Salamanca, abril de 2009. En: http://gredos.usal. es/jspui/bitstream/10366/76289/1/DDTTS_Morato_Garcia_RM_Derecho_de_resistencia.pdf [visitado el 18/08/2010].

${ }^{43}$ Facultad de mando es la genérica denominación utilizada por Thayer Arteaga y Novoa Fuenzalida para referirse al conjunto de facultades con que cuenta el empleador respecto del trabajador, THAYER Arteaga, William; Novoa Fuenzalida, Patricio, Manual de Derecho del Trabajo, Editorial Jurídica de Chile, Santiago de Chile, 1989, p. 168.

${ }^{44}$ Ver definición de empresa en el art. $3^{\circ}$ del Código.

${ }^{45}$ CaAmaño Rojo, Eduardo, "Las transformaciones del trabajo, la crisis de la relación laboral normal y el desarrollo del empleo atípico", Revista de Derecho (Valdivia) vol.18, № 1, 2005, ver especialmente pp. 25 a 30. En: http://www.scielo.cl/scielo.php?script=sci_arttext\&pid=S071809502005000100002\& lng=es\&nrm=iso [visitado el 13/08/2009]. 
de acuerdo con la jurisprudencia judicial y administrativa, en controlar la asistencia, supervigilar la labor del trabajador y darle instrucciones ${ }^{46}$, entre otras manifestaciones. El reglamento interno, en cuanto establece reglas relativas a la organización de la prestación de servicios y emana del empleador, también es manifestación del poder de dirección.

En coincidencia con lo expresado por la Corte Suprema, entre las atribuciones concedidas por el poder de dirección parece posible incluir al ius variandi, esto es, a la facultad del empleador de modificar unilateralmente ciertas condiciones de la prestación de servicios sin menoscabar la situación del trabajador $^{47}$. Y ello, aun cuando prestigiosos autores la consideren una expresión de la facultad de mando distinta del poder de dirección ${ }^{48}$.

La potestad disciplinaria, por su parte, "tiene por objeto mantener el orden de los trabajadores al interior de la organización" ${ }^{49}$. Esta potestad consiste en "la corrección de las conductas contrarias a la disciplina laboral" 50, mediante la adopción de medidas o la aplicación de sanciones en caso que algún

${ }^{46}$ Considerando octavo de la Sentencia de la E. Corte Suprema, recurso de casación en el fondo, 28 de septiembre de 2006, rol 2712-05. En la Word Wide Web: http://www.pjud.cl/modulos/BusqCausas/ BCA_esta402.php? rowdetalle=AAANoPAAOAAA4ITAAD\&consulta $=100 \&$ causa $=2712 / 2005 \&$ numcu $a=24667 \&$ secre $=$ UNICA [visitado el 16/08/2010]. Considerando tercero de la Sentencia de la I. Corte de Apelaciones de Antofagasta, apelación sentencia definitiva, 12 de diciembre de 2005, rol 210-2005. En: http://www.pjud.cl/modulos/BusqCausas/BCA_esta402.php?rowdetalle =AAANoPAAOAAAXf2AA K\&consulta $=100 \&$ causa $=210 / 2005 \&$ numcua $=16380 \&$ secre $=$ LABORAL [visitado el 16/08/2010]. Dictamen de la Dirección del Trabajo, Ord. № 649/22, de 9 de febrero de 2005. En: http://www.dt.gob. cl/legislacion/1611/w3-article-79153.html [visitado el 05/08/2010]. Y Dictamen de la Dirección del Trabajo, Ord. № 0373/010, de 24 de enero de 2007. En: http://www.dt.gob.cl/legislacion/1611/w3article-94354.html [visitado el 05/08/2010].

${ }^{47}$ La Corte Suprema, junto con destacar el carácter excepcional del ius variandi, lo ha reconocido como una manifestación del poder de dirección del empleador. Al respecto sentenció: "Dado su carácter excepcional, se trata de una disposición restrictiva, pues si bien reconoce el poder de dirección del empresario, éste puede ejercer esta facultad sólo respetando los derechos de los trabajadores sobre las condiciones del trabajo, excluyéndose, entonces, todas las modificaciones que sean discriminatorias o que importen un menoscabo para el trabajador". Ver considerando sexto de la sentencia de la E. Corte Suprema, casación en el fondo, 14 de septiembre de 2006, rol 884 de 2005. En: http://www.pjud.cl/ modulos/BusqCausas/ BCA_esta402.php?rowdetalle=AAANoPAANAAAYThAAB\&consulta $=100 \&$ cau $\mathrm{sa}=884 / 2005 \&$ numcua $=23365 \&$ secre $=$ UNICA [visitado 17/08/2010].

${ }^{48}$ En este sentido se pronuncian Lizama Portal, Luis, Derecho del Trabajo, LexisNexis, Santiago de Chile, 2003, pp. 78 y ss.; y ThAYER; NOVOA, Manual, cit. nota n. 43, pp. 168 y ss. Parece posible inscribir en esta misma línea a la Dirección del Trabajo, que en el ord. № 3351/185, de 9 de junio de 1997, dictaminó que "el'ius variandi" no puede en caso alguno dejar de ser una legítima manifestación de la facultad de mando del empleador". En: http://www.dt.gob.cl/legislacion/1611/w3-article-88188.html [visitado el 28/07/2010]. En efecto, y como se puede apreciar, la consideró una manifestación de la facultad de mando, y no de la potestad de dirección.

${ }^{49}$ Lizama, Derecho del Trabajo, cit. nota n. 48, p. 80.

${ }^{50}$ Lizama, Derecho del Trabajo, cit. nota n. 48, p. 80. 
trabajador incurra en falta ${ }^{51}$. En todo caso, estas medidas y sanciones deben estar expresamente previstas en el reglamento interno, según ha dictaminado la Dirección del Trabajo ${ }^{52}$. En este sentido, el reglamento interno es, al mismo tiempo, una manifestación del poder de dirección y del poder disciplinario del empleador.

En síntesis, las facultades del empleador incluyen una serie de atribuciones que, genéricamente, pueden ser reunidas bajo las denominaciones de poder de dirección y poder disciplinario.

\subsection{Titulares de las facultades del empleador}

Explicitado el alcance de las facultades del empleador, corresponde determinar quiénes las detentan. Ante todo debe destacarse que lo importante no es la calidad de empleador, sino el encontrarse jurídicamente habilitado para ejercerlas. Y ello, porque la lesión no proviene del hecho de ser el empleador, sino del ejercicio de las facultades del mismo. Pues bien, esta habilitación jurídica puede provenir del contrato o de la ley, lo que significa que las facultades del empleador respecto de un determinado trabajador se generan por vía contractual o legal ${ }^{53}$. A partir de tales fuentes, es posible afirmar que se encuentran jurídicamente autorizados para ejercer las facultades del empleador al menos tres categorías de sujetos.

El primero de esos sujetos es quien contractualmente tiene el carácter de empleador, es decir, la persona natural o jurídica que utiliza los servicios materiales o intelectuales de otra persona en virtud de un contrato de trabajo ${ }^{54}$. Esto es evidente si se considera que se trata, precisamente, del empleador. Naturalmente, este sujeto cuenta con la plenitud de las facultades propias del empleador y, por lo mismo, a su respecto se cumple el tercero de los requisitos de aplicación del procedimiento de tutela.

\footnotetext{
${ }^{51}$ En similar sentido, Lanata Fuenzalida, Gabriela, Contrato individual de trabajo, LexisNexis, Santiago de Chile, 2006, p. 98.

${ }^{52}$ La Dirección del Trabajo dictaminó, luego de transcribir el artículo 154, números 10 y 11 del Código del Trabajo, lo siguiente: "Así entonces, conforme a estas disposiciones, el empleador sólo podrá aplicar las sanciones de amonestación verbal o escrita y multa de hasta el veinticinco por ciento de la remuneración diaria, como asimismo, el reglamento interno de la empresa deberá contemplar el procedimiento de acuerdo al cual deberá hacerse efectiva esta potestad disciplinaria". Dictamen de la Dirección del Trabajo, ord. № 4968/335, de 27 de noviembre de 2000. En: http://www.dt.gob.cl/ legislacion/1611/w3-article-62410.html [visitado el 10/08/2010].

${ }^{53}$ En similar sentido, la Dirección del Trabajo en la Orden de servicio 09, cit. nota n. 18, instruyó que "la conducta típica que la norma [del art. 385 del Código] sanciona debe ser atribuible a quien ejerce las facultades que la ley le reconoce al empleador, sea que estas facultades se ejerzan por el mismo, por quien lo represente, o por un tercero, en los casos que el mismo empleador o la ley así lo autorice".
}

${ }^{54}$ Art. $3^{\circ}$, letra a), del Código. 
El segundo sujeto jurídicamente autorizado para ejercer las facultades del empleador es la persona que, sin ser contractualmente empleador, se presume de Derecho que lo representa, y que en tal carácter lo obliga con los trabajadores $^{55}$. Como puede suponerse, quien se encuentra en esta situación podrá ejercer todas o sólo algunas de las facultades propias del empleador, dependiendo de la estructura organizacional que se haya dado la empresa de que se trate. Con todo, la cantidad o intensidad de las facultades que le hayan sido conferidas en nada obstan a concluir que a su respecto también se cumple el tercero de los requisitos de aplicación el procedimiento de tutela.

El tercer sujeto autorizado para ejercer las facultades del empleador es la persona que, sin ser contractualmente el empleador, recibe sus servicios bajo el régimen de suministro de trabajadores, es decir, la empresa usuaria. A explicitar dicha afirmación se dedica el siguiente apartado, de modo que poco más abajo se volverá sobre el punto. Por ahora basta con reiterar que, según se afirmó más arriba, la empresa usuaria no tiene la calidad de empleador, pese a lo sostenido por Palavecino ${ }^{56}$. En efecto, entre la empresa usuaria y el trabajador suministrado existe una relación jurídica sui generis, que mixtura aspectos laborales y civiles ${ }^{57}$.

Por el contrario, no están jurídicamente autorizados para ejercer facultades del empleador, por ejemplo, los trabajadores que se encuentran en el mismo nivel jerárquico o en un nivel jerárquico inferior al afectado. Y ello aun cuando, como tantas veces ocurre en la realidad, alguno de esos sujetos en los hechos intenten dirigir, fiscalizar o corregir la actividad de sus compañeros de labores. Y ello porque, simplemente, ni contractual ni legalmente han sido dotados de tales facultades.

Tampoco está jurídicamente autorizado para ejercer facultades del empleador la empresa principal respecto de los trabajadores de la empresa contratista

\footnotetext{
${ }^{55}$ Art. $4^{\circ}$, inciso primero, del Código.

${ }^{56}$ En una postura claramente minoritaria, pero igualmente interesante, Palavecino presenta esta idea del siguiente modo: "En términos reales habrá un trabajador sometido a dos empleadores, repartiéndose entre ellos el complejo haz de derechos y obligaciones que emanan de ambas relaciones de trabajo". Y añade que, aunque formalmente la legislación considere empleador a la empresa de servicios transitorios, "materialmente y paralela al contrato de trabajo de servicios transitorios, se genera una relación de trabajo real y directa entre el trabajador y la empresa usuaria, con derechos y obligaciones recíprocos". Y concluye afirmando que el art. 183-Y del Código califica este último vínculo como una "relación laboral". Ver PALAVECINO, Subcontratación, cit. nota n. 19 , pp. 91 y 92.

${ }^{57}$ Aunque una posición justificada respecto de la naturaleza jurídica de la relación existente entre la empresa usuaria y el trabajador suministrado exceden las posibilidades de este trabajo, conviene advertir desde luego que parece tratarse de un híbrido que se mueve en el límite entre el Derecho del trabajo y el Derecho civil.
} 
o subcontratista que le presta servicios ${ }^{58}$. Ello se debe, según se ha dictaminado judicialmente, a que la empresa principal no cuenta con potestades de empleador respecto de tales trabajadores ${ }^{59}$.

\section{La empresa usuaria ejerce facultades del empleador}

Las disposiciones del Derecho legislado, la opinión de la Dirección del Trabajo y los consensos doctrinarios permiten afirmar, sin lugar a dudas, que la empresa usuaria cuenta con facultades propias del empleador respecto de los trabajadores suministrados por la empresa de servicios transitorios.

En efecto, el Código del Trabajo concede a la empresa usuaria una serie de atribuciones que responden tanto al poder de dirección como al poder disciplinario. En cuanto al primero, prescribe que es obligación de la empresa usuaria controlar la asistencia del trabajador suministrado y organizar y dirigir el trabajo del mismo, dentro de las funciones para las cuales este último fue suministrado (arts. 183-W y 183-X). Por su parte, al disponer que el trabajador suministrado quedará sujeto al reglamento de orden, seguridad e higiene de la empresa usuaria, el Derecho legislado está aludiendo simultáneamente a poderes de dirección y disciplinarias (art. 183-X). A estos dos ámbitos responde también el artículo $183-\mathrm{AB}$, al prescribir que la empresa usuaria es responsable del cumplimiento de las normas relativas a higiene y seguridad en el trabajo derivadas de la Ley sobre Accidentes del Trabajo y Enfermedades Profesionales, en especial, las medidas de prevención de riesgos laborales, pues ello implica que tiene la facultad de impartir a los trabajadores suministrados las órdenes necesarias para evitar que sufran accidentes del trabajo o enfermedades profesionales.

La Dirección del Trabajo, por su parte, luego de revisar las disposiciones que regulan la relación entre la empresa usuaria y el trabajador suministrado, concluye sosteniendo que el propio Código "atribuye a la empresa usuaria algunas de las facultades del empleador directo, la de organizar y dirigir el trabajo, dentro del ámbito de las funciones para las cuales el trabajador fue puesto a su disposición" ${ }^{\prime 60}$.

\footnotetext{
${ }^{58}$ Esta clase de relación triangular se encuentra expresamente regulada en los arts. 183-A y siguientes del Código del Trabajo.

${ }^{59}$ En este sentido se ha pronunciado, precisamente, el Juzgado del Trabajo de San Felipe. Luego de acoger la demanda de tutela de derechos fundamentales en contra de la empresa contratista (considerando decimocuarto), el juzgador la rechaza respecto de la empresa principal porque las órdenes e instrucciones dadas por esta última "fueron ejercidas fuera de una relación laboral, por lo que no se cumple con el requisito establecido en el artículo 485 del Código del Trabajo" (considerando decimotercero). Sentencia del Juzgado del Trabajo de San Felipe, procedimiento de tutela, 28 de octubre de 2009, RIT T-12 de 2009. En: http://www.pjud.cl/modulos/BusqCausas/causas/doc_lab_reformado. php?crr_docfallo=137454\&cod_tribunal=1358\&tip_doc=1 [visitado el 17/08/2010].

${ }^{60}$ Dirección del Trabajo, Orden de Servicio 09, cit. nota n. 18.
} 
La doctrina, por último, parece conteste en reconocer que la empresa usuaria ejerce facultades del empleador respecto de los trabajadores suministrados. Así, por ejemplo, Lizama Portal y Ugarte Cataldo la definen como aquella "que utiliza efectivamente los servicios del trabajador temporal, ejerciendo sobre él la potestad de mando laboral, pagando un precio por ello a la empresa suministradora" ${ }^{\prime 61}$. Ugarte Cataldo reitera esta idea cuando afirma que en el suministro de trabajadores el poder de mando es ejercido por la empresa usuaria del suministro ${ }^{62}$. Gamonal Contreras y Prado López, a su turno, expresan que "durante el trabajo en régimen de servicios transitorios es la usuaria la que ejerce la potestad de mando y bajo cuya subordinación y dependencia labora el trabajador"63. Echeverría y Vergara, por su parte, afirman que en la relación triangular consistente en el suministro de trabajadores las facultades de impartir instrucciones, normas y órdenes en la ejecución del trabajo se le atribuye a la empresa usuaria y, en consecuencia, la facultad de mando se ha transferido de la empresa de servicios transitorios a la empresa usuaria ${ }^{64}$.

En definitiva, resulta posible sostener que la empresa usuaria efectivamente ejerce facultades del empleador $y$, dado que lo relevante no es la calidad de empleador, sino el ejercicio de las facultades de tal, a su respecto se cumple el tercer requisito de aplicación del procedimiento de tutela.

\section{CONClusiones}

De acuerdo con lo que hasta aquí se ha expuesto, la descentralización productiva como fenómeno vinculado con la gestión empresarial y el respeto de los derechos fundamentales como principio inspirador de las recientes reformas en el ámbito laboral, tienen un punto de conexión en la protección de los derechos fundamentales de los trabajadores de servicios transitorios. Ese punto

\footnotetext{
${ }^{61}$ LizAma; Ugarte, Subcontratación, cit. nota n. 20, p. 6.

${ }^{62}$ La idea es expresada por Ugarte Cataldo al identificar las diferencias entre la subcontratación y el suministro de trabajadores. UGARTE, "Sobre relaciones", cit. nota n. 21, pp. 14 y 15.

${ }^{63}$ Gamonal Contreras, Sergio; Prado López, Pamela, El suministro de trabajadores en la nueva ley 20.123. Acerca de la calidad de coempleador y la doble subordinación, p. 12. En: http://www.derecho-trabajo. cl/Ponencias/SERGIO\%20GAMONAL.doc [visitado el 19/08/2010].

${ }^{64}$ Más precisamente, expresan Echeverría y Vergara: "La empresa usuaria ejerce mando sobre el trabajador suministrado. La facultad de despedir corresponde a la ETT como empleador. La facultad de impartir instrucciones, normas y órdenes en la ejecución del trabajo se le atribuye a la empresa usuaria. Al separarse ambas facultades, de despido y de mando en dos sujetos; la ETT y la usuaria, se rompe la relación que permite al empleador invocar su facultad de mando para justificar el despido. La ETT no podrá invocar como causa del despido, el incumplimiento del trabajador, puesto que la facultad de mando se ha transferido a un tercero". Ver EcheverRía, Magdalena; Vergara, Mónica, "La cesión de trabajadores: quiebres en el contrato de trabajo", Gaceta Laboral año/vol 07, núm. 001, Universidad de Zulia, 2001, p. 7.
} 
de conexión consiste en la aplicabilidad del procedimiento de tutela en caso que la empresa usuaria lesione los derechos fundamentales de los trabajadores que le han sido suministrados por la empresa de servicios transitorios.

Lo anterior significa que si la empresa usuaria vulnera los derechos fundamentales de los trabajadores suministrados, queda sometido al procedimiento de tutela establecido en el artículo 485 del mismo texto legal. Esto se debe a que, según se ha mostrado, resulta perfectamente posible afirmar que a su respecto se cumplen cada uno de los requisitos de aplicación de dicho procedimiento. En efecto, y por una parte, esa eventual vulneración se da en el contexto de una relación laboral. Por otra parte, la empresa usuaria se encuentra en situación de afectar el disfrute de los derechos fundamentales expresamente protegidos a través del procedimiento de tutela. Y, por último, esta empresa se encuentra en dicha situación porque, respecto de los trabajadores suministrados, ejerce facultades propias del empleador.

La conclusión recién explicitada exige añadir inmediatamente dos concisos comentarios: uno en el ámbito de la interpretación que conduce a dicha conclusión y otro relativo a las consecuencias de la misma.

En cuanto a lo primero, se podría reprochar que la interpretación ofrecida ha desatendido el tenor literal de la disposición analizada. Nada menos exacto. Como expresa Ferrajoli, la interpretación "siempre es el fruto de una elección práctica respecto de hipótesis interpretativas alternativas" ${ }^{\prime 65}$. En este sentido, y siguiendo ahora a De Asís Roig, cuando existen dudas interpretativas, el tenor literal de un enunciado normativo se erige en límite de la interpretación, en el sentido que las palabras utilizadas expresan lo que el enunciado normativo no puede decir ${ }^{66}$. Como se ha podido advertir a lo largo de estas páginas, el presente trabajo ha respetado ese principio de interpretación, pues en él no se ha sostenido nada contrario a lo expresado en los enunciados normativos citados a lo largo del mismo.

En cuanto a lo segundo, no parece posible, y seguramente tampoco deseable, ocultar que esta conclusión favorece el efectivo disfrute de los derechos fundamentales de los trabajadores. Las consecuencias más importantes de las conclusiones ofrecidas en este trabajo se verifican en el ámbito laboral y, más específicamente, en la regla sobre atenuación de la carga probatoria estatuida

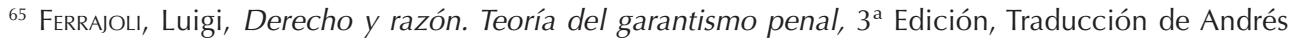
Ibáñez, Perfecto; Ruiz Miguel, Alfonso; Bayón Mohino, Juan Carlos; Terradillos Basoco Juan; Cantarero Bandrés, Rocío, Trotta, España, 1998, pp. 37 y 38.

${ }^{66} \mathrm{Al}$ respecto, textualmente expresa De Asís Roig que, en los casos en que la literalidad de la disposición presente dudas, "lo habitual será que la dimensión semántica proporcione no tanto una información positiva sino negativa, en el sentido de manifestar no ya lo que el enunciado dice sino lo que no puede decir". De Asís Roıg, Rafael, El juez y la motivación en el Derecho, Dykinson, Madrid, 2005, pp. 137 y 138. 
en el artículo 493 del Código. En efecto, y como destaca Ugarte Cataldo, la rebaja en el esfuerzo probatorio se justifica en "el carácter manifiestamente hundido de las conductas lesivas de derechos fundamentales" y en "el entorno probatorio hostil que enfrenta el trabajador que demanda tutela de sus derechos fundamentales ${ }^{\prime 67}$. En ese entendido, admitir la aplicabilidad del procedimiento de tutela a la empresa usuaria viabiliza una más eficaz protección de tales derechos y, por lo mismo, el efectivo disfrute de los mismos.

En todo caso, y como se puede suponer, estas conclusiones no cierran las interrogantes relacionadas con la protección de los derechos fundamentales en el ámbito de la tercerización. Con ella no se responde, por ejemplo, cuál es el camino procesal que se debe seguir para el resguardo de los derechos fundamentales que no se han incluido en el artículo 485. Tampoco se resuelve el problema de la responsabilidad de la empresa de servicios transitorios, en caso que sus trabajadores sean lesionados en el disfrute de estos derechos por parte de la empresa usuaria. La externalización de los servicios es, en este sentido, un campo singularmente fértil para que la academia genere aportes a una mayor comprensión de normas e instituciones del Derecho del trabajo y, por lo mismo, a un mejor funcionamiento de la justicia laboral. En consecuencia, gran parte de la tarea sigue pendiente.

\section{BibLIOGRAFíA}

\section{Libros y artículos}

Ackerman, Mario E., "Contrato de servicios y contrato de trabajo. La protección de la persona en las fronteras del Derecho del trabajo", Revista Latinoamericana de Derecho, Año IV, núm. 7-8, Universidad Nacional Autónoma de México, 2007. En: http://www.juridicas.unam.mx/publica/rev/indice. htm? $r=$ revlad\&n=7 [visitado el 11/07/2010].

Alexy, Robert, Teoría de los derechos fundamentales, Centro de Estudios Políticos y Constitucionales, Madrid, 2001.

CaAmaño Rojo, Eduardo, "La ley de subcontratación y la tutela de los derechos fundamentales de los trabajadores de servicios transitorios", Revista lus et Praxis Año 13 № 2, 2007. En: http://www.scielo.cl/scielo.php?script=sci arttext\&pid $=$ S07180122007000200008\&lng=es\&nrm=iso [visitado el 11/07/2010].

, "Las transformaciones del trabajo, la crisis de la relación laboral normal y el desarrollo del empleo atípico", Revista de Derecho (Valdivia)

${ }^{67}$ UGARTE, "Tutela laboral", cit. nota n. 5, p. 217. 
vol.18, No 1, 2005. En: http://www.scielo.cl/scielo.php?script=sci_arttext\&pid $=$ S0718095020050001000 02\&lng=es\&nrm=iso [visitado el 13/08/2009].

De Asís Roıg, Rafael, Jueces y normas. La decisión judicial desde el ordenamiento, Marcial Pons, Madrid, 1995.

2005. El juez y la motivación en el Derecho, Dykinson, Madrid,

EcheVerría, Magdalena; Vergara, Mónica, "La cesión de trabajadores: quiebres en el contrato de trabajo", Gaceta Laboral año/vol. 07, núm. 001, Universidad de Zulia, 2001. En: http://190.39.165.96/gsdl/collect/artculos/index/assoc/ HASH0148.dir/doc.pdf [visitado el 19/08/2010].

FerRajol, Luigi, Derecho y razón, Teoría del garantismo penal, Traducción de Andrés Ibáñez, Perfecto; Ruiz Miguel, Alfonso; Bayón Mohino, Juan Carlos; Terradillos Basoco Juan; Cantarero Bandrés, Rocío, $3^{\text {a }}$ Edición, Trotta, España, 1998.

Gajardo Harboe, María Cristina, "Nuevo procedimiento de tutela laboral: Los derechos protegidos. El derecho a la vida y a la integridad física y síquica de la persona", Actualidad Laboral enero y febrero, Universidad de Chile, 2009. En: http://www.derecho.uchile.cl/profesores/mengod/actualidad_doc/ ACTUALIDAD\%20LABORAL\%20ENERO\%20Y\%20FEBRERO\%202009.doc [visitado el 17/08/2010].

Gamonal Contreras, Sergio; Prado López, Pamela, El suministro de trabajadores en la nueva Ley $N^{\circ}$ 20.123. Acerca de la calidad de coempleador y la doble subordinación. En: http://www.derecho-trabajo.cl/Ponencias/SERGIO\%20 GAMONAL.doc [visitado el 19/08/2010].

García Figueroa, Alfonso, "La incidencia de la derrotabilidad de los principios iusfundamentales sobre el concepto de Derecho", Diritto \& questioni publiche. En: www.dirittoequestionipubbliche.org/D_Q-3/studi/D_Q-3_studi_Figueroa.pdf [visitado el 22/11/2008].

Lanata Fuenzalida, Gabriela, Contrato individual de trabajo, LexisNexis, Santiago de Chile, 2006.

Lizama Portal, Luis, Derecho del Trabajo, LexisNexis, Santiago de Chile, 2003.

Lizama Portal, Luis; Ugarte Cataldo, José, Subcontratación y Suministro de Trabajadores, LexisNexis, Santiago de Chile, 2007.

Morato García, Rosa María, Derecho de resistencia y ejercicio irregular del poder de dirección. Especial referencia a la autotutela individual en situaciones de riesgo grave e inminente. Tesis para optar al grado de Doctor. Universidad de Salamanca, Salamanca, 2009. En: http://gredos.usal.es/jspui/ bitstream/10366/76289/1/DDTTS_Morato_Garcia_RM_Derecho_de_resistencia .pdf [visitado el 18/08/2010]. 
Palavecino, Claudio, Subcontratación: Régimen Jurídico del Trabajo Subcontratado y de suministro de personal, Jurídica de Chile, Santiago de Chile, 2006.

Peces-Barba Martínez, Gregorio, Derecho y derechos fundamentales, Centro de Estudios Políticos y Constitucionales, Madrid, 1993.

Rivera Santibáñez, José Antonio, "Los efectos de las sentencias constitucionales en el ordenamiento jurídico interno", Estudios Constitucionales Año 4 № 2, Centro de Estudios Constitucionales, 2006. En: http://www.cecoch.cl/htm/ revista/docs/estudiosconst/4n_2_2006/23.pdf. ISSN 0718-0195 [visitado el 20/11/2008].

Rojas MiÑo, Irene, "Los desafíos actuales del derecho del trabajo en Chile", Revista lus et Praxis Año 12 № 1, 2006. En: http://www.scielo.cl/scielo. php? script=sci_arttext\&pid=S071800122006000100010\&lng=es\&nrm=is o [visitado el 25/08/2010].

Ruiz Molleda, Juan Carlos, "En defensa del Tribunal Constitucional: 10 razones jurídicas para resguardar sus potestades interpretativas", Justicia Viva abril, Perú, 2006. En: http://www.justiciaviva.org.pe/publica/10_razones.pdf [visitado el 5/11/2007].

Thayer Arteaga, William; Novoa Fuenzalida, Patricio, Manual de Derecho del Trabajo, Editorial Jurídica de Chile, Santiago de Chile, 1989.

Ugarte Cataldo, José Luis, "Tutela laboral de derechos fundamentales y carga de la prueba", Revista de Derecho (Valparaíso) n. 215-228, 2009. En: http:// www.scielo.cl/scielo.php?script=sci_arttext\&pid=S0718685120090002000 05\&lng=es\&nrm=iso [visitado el 08/07/2010].

"Sobre relaciones laborales triangulares: La subcontratación y el

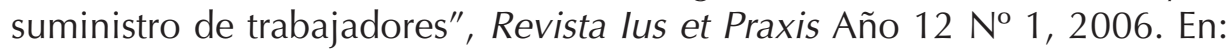
http://www.scielo.cl/scielo.php?script=sci_arttext\&pid=S07180012200600 0100002\&lng=es\&nrm=iso [visitado el 16/08/2010].

\section{Documentos de Historia de la ley}

Biblioteca del Congreso Nacional. Historia de la ley. Ley No 20.087. Sustituye el procedimiento laboral contemplado en el Libro $\mathrm{V}$ del Código del Trabajo. 03 de enero de 2006. En: http://www.bcn.cl/histley/periodos?p=2006 [visitado el 26/07/2010].

Biblioteca del Congreso Nacional. Historia de la ley. Ley No 20.123. Regula trabajo en régimen de subcontratación, el funcionamiento de las Empresas de Servicios Transitorios y el contrato de trabajo de servicios transitorios. 16 de octubre de 2006. En: http://www.bcn.cl/histley/periodos?p=2006 [visitado el 26/07/2010]. 


\section{Documentos de la Dirección del Trabajo}

Dirección del Trabajo. Orden de servicio 09, de 31 de diciembre de 2008, "Imparte instrucciones sobre procedimiento administrativo en caso de denuncia por vulneración de derechos fundamentales, en el marco de la Ley $N^{\circ}$ 20.087, que incorpora procedimiento de tutela laboral, aplicable a las regiones en la cuales ha entrado o entrará en vigencia la reforma procesal laboral incorporada por la Ley $N^{\circ} 20.087^{\prime \prime}$. En: http://www.dt.gob.cl/transparencia/Orden_Servicio_09_31-12-08.doc [visitado el 10/08/2010].

Dirección del Trabajo. Ord. 0373/010, de 24 de enero de 2007. En: http://www. dt.gob.cl/legislacion/1611/w3-article-94354.html [visitado el 05/08/2010].

Dirección del Trabajo. Ord. 649/22, de 9 de febrero de 2005. En: http://www. dt.gob.cl/legislacion/1611/w3-article-79153.html [visitado 05/08/2010].

Dirección del Trabajo. Ord. 4968/335, de 27 de noviembre de 2000. En: http://www.dt.gob.cl/legislacion/1611/w3-article-62410.html [visitado el 10/08/2010].

Dirección del Trabajo. Ord. 3351/185, de 9 de junio de 1997. En: http://www. dt.gob.cl/legislacion/1611/w3-article-88188.html [visitado el 28/07/2010].

\section{Sentencias}

Sentencia, Corte Suprema, recurso de unificación de jurisprudencia, 14 de enero de 2010, rol 7023 de 2009. En: http://www.pjud.cl/modulos/BusqCausas/ BCA_esta402.php?rowdetalle=AAANoPAANAACtgZAAC\&consulta $=100 \&$ ca usa $=7023 / 2009 \&$ numcua $=1555 \&$ secre $=U N I C A$ [visitado el 21/07/2010].

Sentencia, Corte Suprema, recurso de casación en el fondo, 28 de septiembre de 2006, rol 2712-05. En: http://www.pjud.cl/modulos/BusqCausas/BCA_ esta402. php? rowdetalle $=$ AAANoPAAOAAA4ITAAD \& consulta $=100 \&$ causa $=2712 / 2005 \&$ numcua $=24667 \&$ secre $=$ UNICA [visitado el 16/08/2010].

Sentencia, Corte Suprema, casación en el fondo, 14 de septiembre de 2006, rol 884 de 2005. En: http://www.pjud.cl/modulos/BusqCausas/BCA_esta402.p hp? rowdetalle $=$ AAANoPAANAAAYThAAB $\&$ consulta $=100 \&$ causa $=884 / 200$ $5 \&$ numcua $=23365 \&$ secre $=$ UNICA [visitada 17/08/2010].

Sentencia, Corte de Apelaciones de Antofagasta, Apelación sentencia definitiva, 12 de diciembre de 2005, rol 210-2005. En: http://www.pjud.cl/modulos/ BusqCausas/BCA_esta402.php?rowdetalle=AAANoPAAOAAAXf2AAK\&co nsulta $=100 \&$ causa $=210 / 2005 \&$ numcua $=16380 \&$ secre $=$ LABORAL [visitado el 16/08/2010].

Sentencia, Corte de Apelaciones de Valdivia, recurso de protección, 6 de septiembre de 2006, rol 665 de 2006. En: http://productos.legalpublishing. cl/NXT/publishing.dll/A_Juridica/CL_JOLLOL/CL_LSJ00/CL_LSJ06/jad/jad33 ? $\mathrm{fn}=$ document-frame. $\mathrm{htm} \$ \mathrm{f}=$ templates $\$ 3.0$. [visitado el 28/07/2010]. 
Sentencia, Corte de Apelaciones de Valparaíso, recurso de nulidad, 9 de noviembre de 2009, rol 373-2009. En: http://www.pjud.cl/modulos/BusqCausas/ BCA_esta402.php? rowdetalle=AAANoPAANAACuogAAE\&consulta $=100 \&$ causa $=373 / 2009 \&$ numcua $=41337 \&$ secre $=$ REFORMA LABORAL [visitado el 28/07/2010].

Sentencia, Juzgado del Trabajo de San Felipe, tema, 28 de octubre de 2009, RIT T-12 de 2009. En: http://www.pjud.cl/modulos/BusqCausas/causas/doc_ lab_reformado.php?crr_docfallo=137454\&cod_tribunal=1358\&tip_doc $=1$ [visitado el 17/08/2010]. 